\title{
Prevalence, intensity and complications of Microsporidium spores amongst HIV-positive hospital patients in Ilorin, Nigeria
}

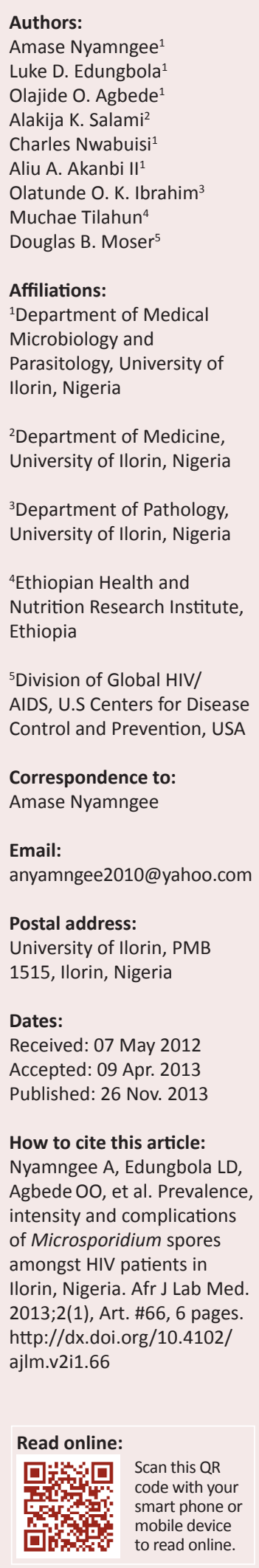

\section{Authors:}

Amase Nyamngee

Muchae Tilahun ${ }^{4}$

Microbiology and

Parasitology, University of

${ }^{2}$ Department of Medicine,

${ }^{3}$ Department of Pathology,

Nutrition Research Institute,

AIDS, U.S Centers for Disease

Correspondence to:

Email:

Postal address:

University of Ilorin, PMB

llorin, Nigeria

Received: 07 May 2012

Accepted: 09 Apr. 2013

How to cite this article: Nyamngee A, Edungbola LD, Agbede 00 , et al. Prevalence, of Microsporidium spores amongst HIV patients in Ilorin, Nigeria. Afr J Lab Med. 2013;2(1), Art. \#66, 6 pages. http://dx.doi.org/10.4102/ ajlm.v2i1.66
Background: Microsporidiasis, which is of great concern for immunocompromised patients, is poorly studied in developing countries.

Objectives: A study was carried out amongst HIV-positive hospital patients and HIVnegative hospital controls in Ilorin, Nigeria, between January 2009 and July 2010 to determine the prevalence and intensity of Microsporidium spores and the complications associated with their presence.

Method: Stool samples from 750 HIV-positive patients and 375 HIV-negative patients were studied using the Chromotrope-2R staining technique. Determination of CD4+ count was performed on the Partec Cyflow SL-3 CD4/8 instrument. Intensity of spores was determined by counting the total number of the spores in a $10 \mu \mathrm{l}$ stained smear of stool. Images were captured with Phenix Microimage Analysis Software and data obtained were analysed using the Statistical Package for the Social Sciences.

Results: The prevalence of Microsporidium isolates amongst the HIV-positive hospital patients was significantly higher (42.4\%) than amongst the HIV-negative controls $(19.2 \%)$ $(p<0.05)$. The intensity of microsporidial spores amongst HIV-positive hospital patients was also significantly higher than amongst the controls $(p<0.05)$. However, the difference in the intensity of spores amongst HIV-positive patients who were on antiretroviral therapy $(n=411)$ and those who were not $(n=339)$ was not significant $(p=0.236)$. Microsporidiasis in HIV infection infection was common amongst patients with with low CD4+ counts, diarrhoea, body rashes and cough.

Conclusion: Both the prevalence and intensity of Microsporidiasis are high amongst HIVpositive hospital patients; campaigns to promote awareness, prevention and control are required. Laboratory testing for microsporidia in HIV patients should be performed routinely so as to identify the organism for prompt medical attention.

\section{Introduction}

Microsporidiasis is recognised by the World Health Organization as being a globally-important medical, public health and socio-economic problem. ${ }^{1,2}$ Microsporidia are obligate and opportunistic intracellular spore-forming parasites which belong to the phylum Protozoa.,4,5 Although there are more than 1000 known Microsporidium species and as many as 100 genera of the group affecting both vertebrates and invertebrates, ${ }^{6}$ there are only 12 species, belonging to 8 genera, that are known to be pathogenic to humans. ${ }^{7,8}$

The first well-documented human case of Microsporidiasis, where Encephalitozoon spp. was detected in a stool sample of a diarrhoea patient, was reported in 1959. ${ }^{9}$ Since then, microsporidia have become increasingly better recognised as opportunistic human pathogens, ${ }^{10,11,12}$ particularly in patients with suppressed immunity, including organ transplant patients and HIV patients. ${ }^{5,13,14}$ Microsporidia can also infect people with competent immune systems, resulting in latent infections. ${ }^{6,15,16}$ In HIV patients, microsporidia have been implicated in intestinal, ocular, pulmonary and renal diseases, and have been shown to cause diarrhea and other adverse health conditions. ${ }^{17,18,19}$

Chronic diarrhoea is common in HIV-positive patients but the enteric pathogens are identified in fewer than $50 \%$ of cases. $5,7,8,20,21,22$ The medical and public health implications of chronic diarrhoea in HIV-positive patients are problematic, especially with regard to the management of HIV with antiretroviral therapies. ${ }^{23,24}$

With the detection of more cases of chronic diarrhoea in HIV-positive patients, 4,12,25,26 Enterocytozoonbieneusi (a species of Microsporidium) is increasingly suspected to be an aetiological 
agent, and has also implicated in the excessive morbidity and mortality. ${ }^{18,26,27,28,29}$ In Portugal, Ferreira et al. ${ }^{30}$ reported a $41.2 \%$ prevalence of microsporidial diarrhoea in HIV patients, calling for better management of diarrhoea in these patients.

There is a paucity of information on microsporidia, particularly in developing countries where no concerted effort has been made to ascertain the prevalence, intensity, mode of transmission and tissue pathology caused by Microsporidiasis, especially amongst HIV patients. In Nigeria, there is no documented information on human microsporidia and Microsporidiasis. The objective of this study was to determine the prevalence and intensity of Microsporidium spores in HIV-positive hospital patients in Ilorin, Nigeria, and to determine the association of Microsporidiasis with other medical conditions amongst these patients.

\section{Research method and design Description of the study area}

This work was carried out at the University of Ilorin Teaching Hospital, a tertiary and referral hospital located in Ilorin, Kwara State, Nigeria.

\section{Study design}

A cross-sectional, hospital-based study was designed and implemented so as to determine which pathogenic microsporidia could be detected in both HIV-positive and -negative patients attending the University of Ilorin Teaching Hospital between January 2009 and July 2010. A sample size of 1125 was calculated using Fisher's formula and based on an estimated $47 \%$ prevalence of diarrhoea amongst HIVpositive patients. ${ }^{5,31}$ The sample comprised 750 HIV-positive and 375 HIV-negative patients, matched 2-to-1 for age, sex and other socio-economic variables. Informed consent was obtained from participants before being enrolled for this study. A structured questionnaire was administered to each patient to collect demographic variables and ARV status, as well as information about other concomitant infections. The patients completed the questionnaire before the samples were collected.

\section{Sampling method}

Simple random-sampling by number randomisation was used to select HIV-positive patients for this study. HIV status of patients was determined based on rapid HIV testing kits. HIV-negative controls were selected by number randomisation amongst all possible matches.

\section{Sample collection and processing}

All participants were screened for HIV-status prior to stool collection. The screening and the collection of the stool samples were done by the researcher and two trained laboratory assistants. Three screening methods were used concurrently to test and confirm HIV-sero-status: (1) Antec HIV test (Antec International Ltd, U.K.), (2) Determine HIV $1 / 2$ test (Inverness Medical, Beijing, China) and (3) Uni-Gold HIV test (Trinity Biotech, Ireland). Confirmation of HIV positivity occurred only when all three tests were reactive for HIV antibodies and confirmation for HIV negativity was when all three tests showed no reaction. For the purposes of this study, patients who showed reactions on one or two of the three test kits were retested, but were excluded if the results remained discordant.

Stool specimens were collected in sterile universal bottles from all patients. For the identification of Microsporidium spores, unconcentrated formalin-fixed stools were stained using the Chromotrope2R staining method. ${ }^{5,32}$ Each stained smear was examined by light microscope under an oil immersion lens. ${ }^{5}$ The Microsporidium photomicrographs and measurement of the spore size were taken according to the manufacturer's instruction, using Phenix Microimage Analysis Software (PMIAS 3.3), Microscope model ME 100. A positive control slide from the Division of Parasitic Diseases of the Centers for Disease Control and Prevention (CDC), Atlanta, Georgia, reference No. UN3373, was compared against the positive samples in this study. In addition, three positive slides were sent to the CDC in Atlanta for confirmation. The intensity of the spores in the stool samples (Figure 1) was determined by counting the total number of spores in a $10 \mu \mathrm{l}$ stained smear of stool on a glass slide. ${ }^{1}$ Counting and authentication of the spores was carried out manually by the lead investigator and three independent co-researchers after blinding on HIV sero-status. The average of the 4 results was taken to be the mean intensity of the spores per $10 \mu \mathrm{l}$ of stool.

\section{Determination of T-cell count}

The CD4+ count was determined using a CD4/8 Cyflow machine (Partec Cyflow SL-3, Germany) according to the manufacturer's instructions. A $3 \mathrm{ml}$ sample of blood in an Ethylenediaminetetraacetic acid (EDTA) tube was inserted into the machine and the CD4/CD8 count of each individual sample was determined.

\section{Data analysis}

The Statistical Package for the Social Sciences (SPSS version 16.00) was used for data anlysis. Prevalence of infection was given in percentages in line with the variables. Chi-square and $95 \%$ confidence interval analysis were the statistical

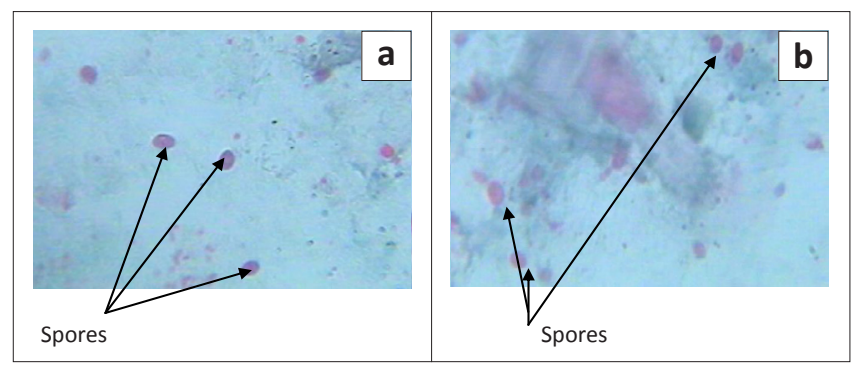

Source: Experimental data from study

FIGURE 1: Images of Microsporidium spores in stool samples from our study. 
tools used to determine significance at a cut-off value of $95 \%$ $(p=0.05)$.

\section{Results}

We enrolled 750 (66.7\%) HIV-positive and 375 (33.3\%) HIVnegative patients. The prevalence of Microsporidium infection amongst the HIV-positive patients was $42.4 \%$, which was significantly higher than the corresponding $19.2 \%$ prevalence in the HIV-negative patients $(p<0.05$; Table 1a). Amongst HIV-positive patients, prevalence of microsporidiasis was significantly lower amongst men than amongst women (39.6\% vs. $44.9 \%, p<0.05)$. Differences in prevalence between men and women amongst HIV-negative patients (19.9\% vs. $18.6 \%)$ and amongst all patients (33.1\% vs. $36.1 \%)$ did not reach statistical significance $(p>0.05)$ (Table $1 b)$.

The prevalence amongst HIV-positive patients who had been on ARVs for between 3-18 months was similar to that amongst patients not on ARVs $(67.6 \%$ vs. $68.2 \%, p>0.05)$ (Table 2). All HIV-positive patients aged 42-61 who were not on ARVs had Microsporidiasis; their counterparts who were on ARVs also had a high prevalence. The prevalence of Microsporidiasis increased with age amongst both groups.

The mean intensity of Microsporidium spores per $10 \mu \mathrm{l}$ of stool amongst the HIV-positive patients who were on ARVs showed no significant difference when compared with those who were not on ARVs (Table 3). The 52-61 age group demonstrated the highest intensity of Microsporidium spores (mean \pm standard deviation: $277 \pm 94.0$ ) amongst HIV-positive patients who were on ARVs. Patients not on ARVs had the highest intensity of spores $(234 \pm 88.0)$ in the 32-41 age group. The difference in intensity amongst those patients on ARVs and those not on ARVs in relation to age was not statistically significant $(p>0.05)$. In both

TABLE 1a: Prevalence of Microsporidiasis by age amongst HIV-positive and -negative patients ( $n=1125)$.

\begin{tabular}{lcccccc}
\hline Age (years) & \multicolumn{2}{c}{ HIV-positive patients } & & \multicolumn{2}{c}{ HIV-negative patients } \\
\cline { 2 - 3 } \cline { 6 - 7 } & No. Examined & No. (\%) +ve & & No. Examined & No. (\%) +ve \\
\hline$\leq 1$ & 11 & $3(27.3)$ & & 6 & $2(33.3)$ \\
$2-11$ & 53 & $14(26.4)$ & & 28 & $0(0.00)$ \\
$12-21$ & 175 & $56(32.0)$ & & 108 & $14(13.0)$ \\
$22-31$ & 238 & $76(31.9)$ & & 113 & $20(17.7)$ \\
$32-41$ & 152 & $89(58.6)$ & & 64 & $27(42.2)$ \\
$42-51$ & 99 & $63(63.4)$ & & 47 & $5(10.6)$ \\
$52-61$ & 22 & $17(77.3)$ & & 9 & $4(44.4)$ \\
\hline Total & 750 & $318(42.4)$ & & 375 & $\mathbf{7 2 ( 1 9 . 2 )}$ \\
\hline
\end{tabular}

+ve; Positive for Microsporidiasis groups, intensity of Microsporidium spores was inversely associated with CD4+ count; age groups with low CD4+ had high intensity of Microsporidium (Table 3).

Amongst HIV-positive patients, those with diarrhoea had the highest prevalence of Microsporidiasis amongst all those with a single condition (95.6\%) (Table 4). This was followed closely by those with body rashes (91.7\%). Amongst those with multiple conditions, those with diarrhoea and body rashes (with and without cough) had $100 \%$ prevalence of Microsporadiasis.

\section{Ethical considerations}

\section{Ethical clearance}

Ethical clearance was sought and obtained from the Ethical Review Committee of the University of Ilorin Teaching Hospital with reference number, UITH/CAT/189/817.

\section{Informed consent}

The purpose of this study was explained in detail to all subjects during the study. Participation was voluntary and the confidentiality of information given for the purpose of this study was guaranteed.

All subjects were also apprised of the benefits of knowing their HIV status, CD4+ counts, and medical complications.

\section{Data protection}

All specimen collected were preserved according to international standards and kept under iced Hydrogen refrigeration in the data storage chamber of the University of Ilorin Teaching Hospital.

\section{Trustworthiness}

Independent researchers confirmed and counted the spores to address the issue of credibility and the average of the four counts was recorded. We also obtained a control slide of the organism from the CDC in order to ensure that the organism was identified correctly. To address the issues of dependability and confirmability, we relied on an average independent count and the control slide.

\section{Discussion}

Our findings revealed a high prevalence (42.4\%) and significant intensity of Microsporidiasis amongst the HIVpositive patients, thus complicating morbidity and mortality

TABLE 1b: Prevalence of Microsporidiasis amongst HIV-positive and -negative patients by gender $(n=1125)$.

\begin{tabular}{|c|c|c|c|c|c|}
\hline \multirow[t]{2}{*}{ Infection status } & \multicolumn{2}{|c|}{ Male } & \multicolumn{2}{|c|}{ Female } & \multirow{2}{*}{$\begin{array}{c}\text { Total } \\
\text { No. }(\%)+v e\end{array}$} \\
\hline & No. Examined & No. $(\%)+$ ve & No. Examined & No. $(\%)+v e$ & \\
\hline HIV-positive patients $(n=750)$ & 356 & $141(39.6)$ & 394 & $177(44.9)$ & $218(42.4)$ \\
\hline HIV-negative patients $(n=375)$ & 176 & 35 (19.9) & 199 & $37(18.6)$ & $72(19.2)$ \\
\hline Total $(n=1125)$ & 532 & $176(33.1)$ & 593 & $214(36.1)$ & 390 (34.7) \\
\hline
\end{tabular}

+ve; Positive for Microsporidiasis 
in areas where HIV is common. The infection was detected across genders and age groups indicating that microsporidia are ubiquitous as suggested previously. ${ }^{6,16}$ Whilst prevalence increased with age amongst the HIV-positive patients, there was was not a clear trend amongst the HIV-negative controls. We observed that the intensity of spores was highest amongst the HIV-positive patients, especially in the very old and in those with very low $(<10)$ CD4+ counts, suggesting a relationship with the level of CD4+ counts in HIV-positive patients ${ }^{19}$. Previous studies have reported a high intensity of microsporidia in HIV-positive patients due to their low immune status, which created a condition for the rapid replication of Microsporidium spores ${ }^{12}$.

Amongst the HIV-positive patients, it was observed that $95.6 \%$ of those reporting with diarrhoea were positive for

TABLE 2: Prevalence of Microsporidiasis amongst HIV-positive patients by age and ARV status $(n=750)$.

\begin{tabular}{lccccc}
\hline Age (Years) & \multicolumn{2}{c}{ On ARVs } & & \multicolumn{2}{c}{ Not on ARVs } \\
\cline { 2 - 3 } \cline { 6 - 7 } & $\begin{array}{c}\text { No. \% } \\
\text { Examined }\end{array}$ & $\begin{array}{c}\text { No. (\%) } \\
\text { +ve }\end{array}$ & & $\begin{array}{c}\text { No. (\%) } \\
\text { Examined }\end{array}$ & $\begin{array}{c}\text { No. (\%) } \\
\text { +ve }\end{array}$ \\
\hline$\leq 1$ & $0(0.0)$ & $0(0.0)$ & & $11(100.0)$ & $3(27.3)$ \\
$2-11$ & $4(7.5)$ & $1(25.0)$ & & $49(92.5)$ & $13(26.5)$ \\
$12-21$ & $82(46.9)$ & $38(46.3)$ & & $93(53.1)$ & $43(46.2)$ \\
$22-31$ & $148(62.2)$ & $90(60.8)$ & & $90(37.8)$ & $55(61.1)$ \\
$32-41$ & $102(67.1)$ & $92(90.2)$ & & $50(32.9)$ & $48(96.0)$ \\
$42-51$ & $61(61.6)$ & $46(75.4)$ & & $38(36.6)$ & $38(100.0)$ \\
$52-61$ & $14(63.6)$ & $11(78.6)$ & & $8(22.7)$ & $8(100.0)$ \\
\hline Total & $411(54.8)$ & $\mathbf{2 7 8 ( 6 7 . 6 )}$ & & $\mathbf{3 3 9 ( 4 5 . 2 )}$ & $\mathbf{2 1 7}(68.2)$ \\
\hline
\end{tabular}

+ve; positive for Microsporidiasis, ARV; Antiretroviral therapy
Microsporidium, which may implicate microsporidia as an aetiologic agent in the diarrhoea that is seen in these immunocompromised patients. This is in line with previous suggestions concerning the need for more investigations of the aetiologic agent of this diarrhoea amongst HIV-postive patients. ${ }^{5,18}$ A $100 \%$ prevalence of Microsporidium spores was seen amongst HIV-positive patients who had both diarrhoea and body rashes (with or without cough). Other conditions associated with Microsporidium were body rashes only (91.7\%), diarrhoea with cough (77\%) and body rashes with cough $(70.0 \%)$, stimulating interest about the involvement of Microsporidiasis in other complications amongst HIV patients. This is contrast with the findings of Nkinin et al. ${ }^{16}$ who reported an unexpectedly high prevalence (67.5\%) of Microsporidiasis in 126 immunocompetent patients in Cameroon in 2007, but found no clinical manifestations in these individuals.

Presently, there is no effective treatment for treating Microsporidiasis which has made control difficult, even in areas where there is knowledge regarding Microsporidium infections in humans. ${ }^{23,24}$

\section{Limitations of the study}

This study is subject to several limitations. First, measuring the intensity of spores in stool samples is somewhat subjective and variable; to reduce these issues, we had 4 experts independently count spores and averaged the results. Second, the study was hospital-based, limiting our

TABLE 3: Intensity of Microsporidium spores in relation to age, CD4+ count and antiretroviral therapy status amongst HIV-positive patients $(n=750)$.

\begin{tabular}{|c|c|c|c|c|c|c|}
\hline \multirow[t]{2}{*}{ Age } & \multicolumn{2}{|c|}{ Number of Patients } & \multicolumn{2}{|c|}{ Mean \pm SD Intensity of Spores } & \multicolumn{2}{|c|}{ Mean \pm SD CD4+ Cell Count } \\
\hline & On ARVs $(n=411)$ & Not on ARVs $(n=339)$ & On ARVs & Not on ARVs & On ARVs & Not on ARVs \\
\hline$\leq 1$ & 0 & 11 & N/A & $16 \pm 5.2$ & N/A & $891 \pm 304.4$ \\
\hline $2-11$ & 4 & 14 & $106 \pm 48.0$ & $140 \pm 57.0$ & $916 \pm 311$ & $544 \pm 198.3$ \\
\hline $12-21$ & 82 & 93 & $128 \pm 51.0$ & $164 \pm 59.0$ & $371 \pm 92$ & $263 \pm 72.6$ \\
\hline $22-31$ & 148 & 90 & $194 \pm 58.0$ & $201 \pm 62.0$ & $212 \pm 81$ & $145 \pm 58.4$ \\
\hline $32-41$ & 102 & 50 & $234 \pm 88.0$ & $244 \pm 82.0$ & $124 \pm 53$ & $112 \pm 21.1$ \\
\hline $52-61$ & 14 & 8 & $211 \pm 66.0$ & $277 \pm 94.0$ & $131 \pm 56$ & $11 \pm 3.3$ \\
\hline
\end{tabular}

SD; standard deviation, ARV; antiretroviral therapy

TABLE 4: Association of Microsporidiasis with other disease conditions in HIV-positive cases.

\begin{tabular}{|c|c|c|c|c|c|}
\hline S/No. & Disease Conditions & $\begin{array}{l}\text { No examined in each } \\
\text { case }(n)\end{array}$ & $\begin{array}{l}\text { No. }(\%)+v e \text { for } \\
\text { microsporidia }\end{array}$ & $\begin{array}{l}\text { CD4+ range for } \\
\text { microsporidia } \\
\text { +ve samples }\end{array}$ & $\begin{array}{l}\text { Mean } \pm \text { SD of CD4+ } \\
\text { for microsporidia } \\
\text { +ve samples }\end{array}$ \\
\hline 1 & Pregnancy & 28 & $21(75.0)$ & 234 & $127 \pm 76$ \\
\hline 3 & Tumour cells & 9 & $4(44.4)$ & 132 & $96 \pm 50$ \\
\hline 4 & Diarrhoea & 318 & $304(95.6)$ & 120 & $87 \pm 48$ \\
\hline 5 & Body rashes & 216 & $198(91.7)$ & 103 & $74 \pm 36$ \\
\hline 7 & General body weakness & 192 & $93(48.4)$ & 243 & $92 \pm 36$ \\
\hline 8 & Diarrhoea and cough & 296 & $228(77.0)$ & 181 & $86 \pm 42$ \\
\hline 9 & Fever and diarrhoea & 396 & $209(52.8)$ & 172 & $76 \pm 28$ \\
\hline 10 & Diarrhoea and body rashes & 298 & $298(100.0)$ & 114 & $69 \pm 23$ \\
\hline 11 & Body rashes and cough & 273 & $191(70.0)$ & 111 & $62 \pm 21$ \\
\hline 12 & Cough, diarrhoea and body rashes & 302 & $302(100.0)$ & 97 & $11 \pm 6$ \\
\hline
\end{tabular}


inference to the general population. Third, irregular power supply may have adversely affected some of our samples; this was reduced through the provision of an alternative power supply.

\section{Recommendations}

We recommend that routine laboratory screening be performed for microsporidia in the hospital setting and that positive isolates be made notifiable. More studies on the aetiology of Microsporidiasis (under light- and electron microscopy) should be undertaken, which should include histopathology study of different organs at autopsy.

\section{Conclusion}

We found a high prevalence and intensity of microsporidia amongst HIV-positive patients, especially amongst those with diarrhoea, body rashes and/or cough. These findings should provide base-line information for further studies and provoke interest in investigations of microsporidia that aim at determining the mode of infection, pathogenicity and treatment as well as prevention and control.

Health education campaigns to promote awareness, prevention and control of Microsporidiasis should be conducted regularly, particularly amongst HIV-positive patients as well as medical, public health and laboratory personnel. Positive results for microsporidia obtained through routine laboratory screening in hospitals should be notifiable. Finally, based on the prevalence and implications of microsporidial infection as observed in this study, there is a need for the development of an ideal drug for the treatment of Microsporidiasis.

\section{Acknowledgements}

I would like to acknowledge the help received from the Division of Parasitic Diseases of the CDC, Atlanta, USA, for providing the control slide of Microsporidium species which was essential for the success of this study. I also appreciate the support of Mr Tunde Odewale, the Chief laboratory scientist of the Department of Medical Microbiology and Parasitology, University of Ilorin, for his laboratory assistance in the preparation of permanent slides.

\section{Competing interests}

The authors declare that they have no financial or personal relationship(s) which may have inappropriately influenced them in writing this article.

\section{Authors' contributions}

A.N. (University of Ilorin) designed the study, conducted the research work, collected the samples, analysed the data, wrote the draft and submitted the final manuscript. L.D.E. (University of Ilorin) supervised the entire work from the beginning and was involved fully in both the identification of the organisms and the write-up.O.O.A. (University of Ilorin) supervised the study design and implementation. A.K.S. (University of Ilorin) participated in the sample collection and identification of the complications, as well as contributing to the draft.C.N. (University of Ilorin) participated in the study design, as well as in the sampling, examination and identification of the positive samples. He also edited the write-up. A.A.A. (University of Ilorin) participated in the sample collection and analysis, as well as editing the final write-up. O.O.K.I. (University of Ilorin) participated in both sample collection and analysis. M.T. (Ethiopian Health and Nutrition Research Institute) read the draft and made corrections with regard to the laboratory procedures. D.B.M. (Division of Global HIV/AIDS, CDC) edited the manuscript.

\section{References}

1. Wolk DM, Schneider SK, Wengenack NL, et al. Real-time PCR method for detection of Encephalitozoon intestinalis from stool specimens. J Clin Microbiol. 2002;40(11):3922-3928. http://dx.doi.org/10.1128/JCM.40.11.3922-3928.2002, PMid:12409353, PMCid:139654

2. Webster JD, Miller MA, Remulapalli V. Encephalitozoon cuniculi-associated placentitis and perinatal death in an Alpaca (Lama pacos). Vet Pathol. 2008;45(2): 255-258. http://dx.doi.org/10.1354/vp.45-2-255, PMid:18424843

3. Bryan RT. Microsporidiosis as an AIDS-related opportunistic infection. Clin Infect Dis. 1999;21 Suppl 1:S62-S65. http://dx.doi.org/10.1093/clinids/21. Supplement_1.S62

4. Waywa $D$, Kongkriengdaj $S$, Chaidatch $S$, et al. Protozoan enteric infection in AIDS related diarrhoea in Thailand. Southeast Asian J Trop Med Public Health. 2001;32Suppl 2:151-155. PMid:12041580

5. Didier ES. Microsporidiosis: an emerging and opportunistic infection in humans and animals. Acta Trop. 2005;94(1):61-76. http://dx.doi.org/10.1016/j. actatropica.2005.01.010, PMid:15777637

6. Abreu-Acosta N, Lorenzo-Morales J, Leal-Guio Y, et al. Enterocytozoon bieneusi (microsporidia) in clinical samples from immuno-competent individuals in Tenerife, Canary Islands, Spain. Trans R Soc Trop Med Hyg. 2005;99(11):848-855. http://dx.doi.org/10.1016/j.trstmh.2005.05.010, PMid:16111728

7. Bryan RT, Schwartz DA. Epidemiology of microsporidiosis. In: Wittner M, editor. The Microsporidia and Microsporidiosis. Herdon, Virginia: ASM Press, 1999; $p$. 502-516.

8. Didier ES, Stovall ME, Green LC, et al. Epidemiology of microsporidiosis: sources and modes of transmission. Vet Parasitol. 2004;126(1-2):145-166. http://dx.doi. org/10.1016/j.vetpar.2004.09.006, PMid:15567583

9. Matsubayashi H, Koike T, Mikata I, et al. A case of encephalitozoon-like body infection in man. AMA Arch Pathol. 1959;67(2):181-187. PMid:13616827

10. Desportes I, Le Charpentier Y, Galian A, et al. Occurrence of a new microsporidian: Enterocytozoon bieneusi n. g., n. sp., in the enterocytes of a human patient with AIDS. J Protozool. 1985;32(2):250-254. PMid:4009510

11. Achbarou A, Ombrouck C, Gneragbe T, et al. Experimental model for human intestinal microsporidiosis in interferon gamma receptor knockout mice infected
by Encephalitozoon intestinalis. Parasite Immunol. 1996;18(8):387-392. http:// dx.doi.org/10.1046/j.1365-3024.1996.d01-128.x, PMid:9229392

12. Batman PA, Kotler DP Kapembwa MS, et al. HIV enteropathy: crypt stem and transit cell hyperproliferation induces villous atrophy in HIV/Microsporidiainfected jejunal mucosa. AIDS. 2007;21(4):433-439. http://dx.doi.org/10.1097/ QAD.0b013e3280142ee8, PMid:17301561

13. Kotler DP, Orenstein JM. Prevalence of intestinal microsporidiosis in HIV-infected individuals referred for gastroenterological evaluation. Am J Gastroenterol. 1994;89(11):1998-2002. PMid:7942725

14. Lores B, Lopez-Miragaya I, Arias C, et al. Intestinal microsporidiosis due to Enterocytozoon bieneusi in elderly human immunodeficiency virus-negative patients from Vigo, Spain. Clin Infect Dis. 2002;34(7):918-921. http://dx.doi. org/10.1086/339205, PMid:11880956

15. Albrecht $\mathrm{H}$, Sobottka I. Enterocytozoon bieneusi infection in patients who are not infected with human immunodeficiency virus. Clin Infect Dis. 1997;25(2):344350. http://dx.doi.org/10.1086/516920

16. Nkinin SW, Asonganyi T, Didier ES, et al. Microsporidian infection is prevalent in healthy people in Cameroon. J Clin Microbiol. 45(9):2841-2846. http://dx.doi. org/10.1128/JCM.00328-07, PMid:17609328, PMCid:2045255

17. Asmuth DM, De Girolami PC, Federman M. Clinical features of microsporidiosis in patients with AIDS. Clin Infect Dis. 1994;18(5):819-825. http://dx.doi. org/10.1093/clinids/18.5.819, PMid:7915548

18. Botterel F, Minozzi C, Vittecoq D, et al. Pulmonary localization of Enterocytozoon bieneusi in an AIDS patient: case report and review. J Clin Microbiol. 2002;40(12):4800-4801. http://dx.doi.org/10.1128/JCM.40.12.4800-4801.2002, PMid:12454201, PMCid:154589 
19. Graczyk TK, Johansson MA, Tamang L, et al. Retrospective species identification of microsporidian spores in diarrheic faecal samples from human immunodeficiency virus/AIDS Patients by multiplexed fluorescence in situ hybridization. I Clin virus/AIDS Patients by multiplexed fluorescence in situ hybridization. J Clin
Microbiol. 2007:45(4):1255-1260. http://dx.doi.org/10.1128/JCM.01975-06, Microbiol. 2007;45(4):1255-1260.
PMid:17287331, PMCid:1865804

20. Pol S, Romana CA, Richard S, et al. Microsporidia infection in patients with the human immunodeficiency virus and unexplained cholangitis. N Engl J Med. 1993;328(2):9599. http://dx.doi.org/10.1056/NEJM199301143280204, PMid:8416439

21. Bern C, Kawai V, Vargas D, et al. The epidemiology of intestinal microsporidiosis in patients with HIV/AIDS in Lima, Peru. J Infect Dis. 2005;191(10):1658-1664. $\mathrm{http}: / /$ dx.doi.org/10.1086/429674, PMid:15838792

22. Endeshaw T, Kebede A, Verweij JJ, et al. Intestinal microsporidiosis in diarrhoeal patients infected with human immunodeficiency virus-1 in Addis Ababa, Ethiopia. jpn J Infect Dis. 2006;59(5):306-310. PMid:17060696

23. Chizhikov V, Rasooly A, Chumakov K, et al. Microarray analysis of microbial virulence factors. Appl Environ Microbiol. 2001;67(7):3258-3263. PMid:11425749, PMCid:93008

24. Didier ES, Weiss LM. Microsporidiosis: current status. Curr Opin Infect Dis. 2006;19(5):485-492. http://dx.doi.org/10.1097/01.qco.0000244055.46382.23,P Mid:16940873

25. Conteas CN, Berlin OG, Lariviere MJ, et al. Examination of the prevalence and seasonal variation of intestinal microsporidiosis in the stools of persons with chronic diarrhea and human immunodeficiency virus infection. Am J Trop Med Hyg. 1998;58(5):559-561. PMid:9598441
26. Leelayoova S, Subrungruang I, Suputtamongkol Y, et al. Identification of genotypes of Enterocytozoon bieneusi from stool samples from human immunodeficiency virus-
infected patients in Thailand. J Clin Microbiol. 2006;44(8):3001-3004. http://dx.doi. org/10.1128/JCM.00945-06, PMid:16891527, PMCid:1594660

27. Liguory O, Sarfati C, Derouin F, et al. Evidence of different Enterocytozoon bieneusi genotypes in patients with and without human immunodeficiency virus infection. Clin Microbiol. 2001·39(7):2672-2674 http//dx doi.org/10.1128/JCM.39.7.2672 2674.2001, PMid:11427592, PMCid:88208

28. Menotti J, Cassinat B, Porcher R, et al. Development of a real-time polymerase-chainreaction assay for quantitative detection of Enterocytozoon bieneusi DNA in stool specimens from immuno-compromised patients with intestinal microsporidiosis. J Infect Dis. 2003;187(9):1469-1474. http://dx.doi.org/10.1086/374620 PMid:12717629

29. Walker M, Kublin JG, Zunt JR. Parasitic central nervous system infections in immunocompromised hosts: malaria, microsporidiosis, leishmaniasis, and African trypanosomiasis. Clin Infect Dis. 2006;42(1):115-125. http://dx.doi org/10.1086/498510, PMid:16323101, PMCid:2683841

30. Ferreira FM, Bezerra L, Santos MB, et al. Intestinal microsporidiosis: a current infection in HIV-seropositive patients in Portugal. Microbes Infect. 2001;3(12):1015-1019.

31. Araoye MO. Research methodology with statistics for health and social sciences. 4579(01)01465-4

32. Chioralia G, Trammer T, Kampen $\mathrm{H}$, et al. Relevant criteria for detecting microsporidia in stool specimens. J Clin Microbiol. 1998;36(8):2279-2283. PMid:9666005 PMCid:105031 